\title{
AN ELECTROMAGNETIC MICRO-UNDULATOR
}

\author{
A. Nassiri \\ Advanced Photon Source \\ L. R. Turner \\ Energy Technology Division \\ Argonne National Laboratory, 9700 South Cass Avenue, Argonne, Illinois 60439 USA $\mathrm{O}$ "
}

\section{Abstract}

Microfabrication technology using the LIGA (a German acronym for Lithography, Electroforming, and Molding) process offers an attractive alternative for fabricating precision devices with micron-sized features. One such device is a mm-sized micro-undulator with potential applications in a table-top synchrotron light source for medical and other industrial uses. The undulator consists of a silver conductor embedded in poles and substrate of nickel-iron. Electromagnetic modeling of the undulator is done using the eddy-current computer code ELEKTRA. Computations predict a field pattern of appropriate strength and quality if the current can be prevented from being shunted from silver by the nickel-iron poles either through insulation or through slotted poles. The design of the undulator along with the computational results are discussed.

\section{INTRODUCTION}

Development of table-top synchrotron light sources for medical applications and industrial usage have been recognized by many in the synchrotron radiation community to play a key role in providing compact, reliable, and cost-effective accelerators for these applications. Compact table-top synchrotron radiation sources have many applications ranging from hospital-based medical diagnostic imaging, cancer therapy, biological crystal studies, surface and catalytic studies, to $\mathrm{x}$-ray lithography for microcircuit production. Also medical applications of free-electron lasers (FELs) with their variable-output-wavelength property, have attracted the interest of researchers in medicine and biology. With variable wavelength FEL, one may ascertain that a given wavelength may be more readily absorbed by one tissue type than by another. It is thus possible to identify critical wavelengths for biomedical use. Such wavelengths could then be incorporated in the design of chemical or other lasers for use in clinical therapies. Toward this goal, a group of researchers have begun to study methods of producing synchrotron radiation using compact accelerator devices [1].

An important par of these studies is the design, construction. and testing of a "micro-undulator" with a period of one millimeter. Undulators and wigglers are devices that are inserted into an electron or positron beam to produce $x$ rays. The magnetic field of such an insertion device is transverse to the beam direction and alternates periodically along the beam direction. The field causes the particles of the beam to oscillate and thereby generate $x$-rays.

\section{DEEP X-RAY LITHOGRAPHY}

The undulator will be fabricated using the deep $x$-ray lithograhy (LIGA) process [2]. In LIGA, $x$-rays with a wavelength less than $1 \mathrm{~nm}$ are used to expose a photosensitive layer, typically polymethylmethacrylate (PMMA). The PMMA is usually applied over a plating base, and when the exposed PMMA regions are removed in a highly selective developer, metal can be electroplated into the PMMA recesses defined by the $x$-rays. The short wavelength minimizes diffraction, and the metal features can be electroplated several hundred microns high with edge runouts of less than 0.1 microns [3].

\section{MICRO-UNDULATOR}

The undulator can operate in the electron beam from the linac of the Advanced Photon Source (APS) at Argonne National Laboratory. With the positron target retracted from the beamline, the linac could accelerate electrons to an energy of $650 \mathrm{MeV}$. The material properties of this undulator are given in section III of Ref. [3]. A summary of the micro-undulator geometrical and operating parameters are shown in Table 1.

Table 1: Micro-undulator Parameters

\begin{tabular}{ll} 
Parameter & Value \\
\hline Period & $1.0 \mathrm{~mm}$ \\
Gap & $0.6 \mathrm{~mm}$ \\
Pole height & $0.2 \mathrm{~mm}$ \\
Pole thickness & $0.3 \mathrm{~mm}$ \\
Pole width & $0.7 \mathrm{~mm}$ \\
Beam energy & $650 \mathrm{MeV}$ \\
Deflection parameter & 0.047 \\
Field strength & $0.5 \mathrm{~T}$ \\
Excitation current & $280 \mathrm{~A}$ \\
Excitation pulse length & $10-20 \mu \mathrm{sec}$
\end{tabular}

A 40-micron slot is cut in each 0.3-mm-wide pole to prevent current from the silver conductor shorting across the nickel-iron pole. The winding pattern is shifted one half period between the top and bottom halves of the undulator

The submitted manuscripe has been created by the University of Chicugo as Operator of Argonne National Laboratory ("Argonne") under Contract No. W-31-109-ENG-38

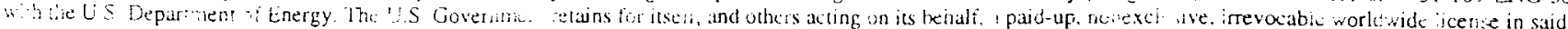
article to reproduce. prepare derivative works. jistribute copies to the public, and perform publicly and display publicly. by or on behalf of the Government. 


\section{DISCLAIMER}

This report was prepared as an account of work sponsored by an agency of the United States Government. Neither the United States Government nor any agency thereof, nor any of their employees, makes any wartanty, express or implied, or assumes any legal liability or responsibility for the accuracy, completeness, or usefulness of any information, apparatus, product, or process disclosed, or represents that its use would not infringe privately owned rights. Reference herein to any specific commercial product, process, or service by trade name, trademark, manufacturer, or otherwise does not necessarily constitute or imply its endorsement, recommendation, or favoring by the United States Government or any agency thereof. The views and opinions of authors expressed herein do not necessarily state or reflect those of the United States Government or any agency thereof. 


\section{DISCLAIMER}

Portions of this document may be illegible in electronic image products. Images are produced from the best available original document. 
so that for the two halves, the currents in the beam direction oppose each other, but in the transverse direction, currents flow in the same direction. Earlier designs with current in the same direction top and bottom led to a field gradient acros's the central region of the undulator. The geometry of one period of the micro-undulator, in perspective view, is shown in Figure 1. In this figure, the silver conductors are arranged so that currents above and below the poles flow in opposite directions axially but in the same direction transversely. The slots in the nickel-iron poles prevent current flowing across the poles.
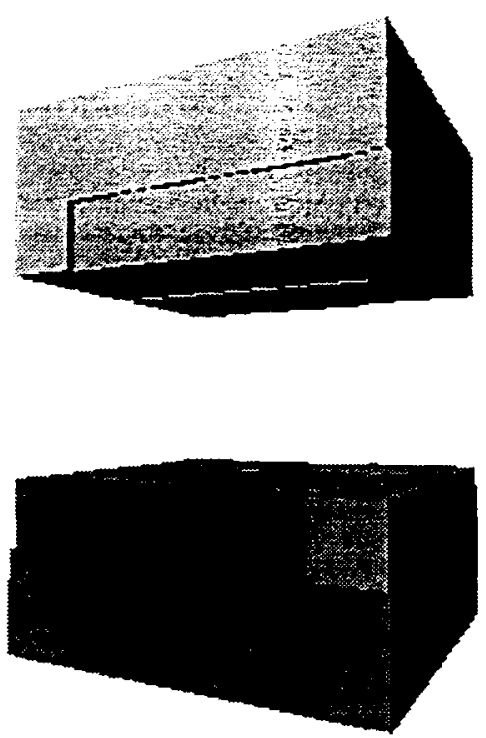

Figure 1: Perspective view of one period of the micro-undulator.

\section{ELECTROMAGNETIC MODELING}

Numerical computations were performed with the 3dimensional eddy-current code ELEKTRA. One period of the micro-undulator was modeled axially by applying a flux-tangential boundary condition on the two faces of the undulator one period apart. Current was determined by using boundary conditions to specify a difference in electric scalar potential (voltage) between the two faces. Since the silver conductors. the nickel-iron poles, and the substrate are conducting. current ian flow from one into the other. Were it not for the slots in the poles of the undulator, considerable current would flow through the poles, greatly impairing its behavior as an undulator. The Lorentz-Gauge solution option of ELEKTRA was used to determine the solution for the steady-state $A C$ problem.

An earlier computation. treating the silver as a driven conductor with a specined current and the nickel-iron as a vector potential region with no net current. was used to consider the situation where the silver was insulated from the substrate. but that approas could not treat current sharing and current shunting be:ween the materials.
Because of the high current densities involved, the undulator will be run only in a pulsed mode; in the modeling it was driven by a $50-\mathrm{kHz}$ steady-state $\mathrm{AC}$ source.

\section{COMPUTATIONAL RESULTS}

Since the gap of this undulator $(0.6 \mathrm{~mm})$ is larger than the half-period $(0.5 \mathrm{~mm})$, the undulator is not efficient; the mid-plane field is small compared to the average pole-topole field. Within the mid-plane, the field is fairly uniform transversely across the central region. Figure 2 shows a contour plot of the flux density over one period. Lines show contours of equal $B_{y}$ in the $x-z$ plane. Figure 3 shows a contour plot of the flux density over one period. Lines shows contours of equal $B_{y}$ in the $y-z$ plane. Figure 4 shows field variation in the beam direction (arbitrary vertical scale).

\section{THE TEN-SCALE MODEL}

As described in Ref. [4], a seven-period, ten-times scale model was designed and fabricated by EDM (Electrode Discharge Machining) using 1010 steel for the substrate and insulated copper wire for the conductor. The model was measured using a Hall probe along the beamaxis of the undulator. In the design, no effort was made to correct end effects, so the measurements were taken only over the central four periods. Results from the measurements are summarized in Figure 5. The model was driven with a current of $10 \mathrm{~A}$ from a DC power supply to avoid overheating of the iron. This gave a peak field of $25.5 \mathrm{G}$, in agreement with the $26.6 \mathrm{G}$ predicted by a 2-dimensional computation.

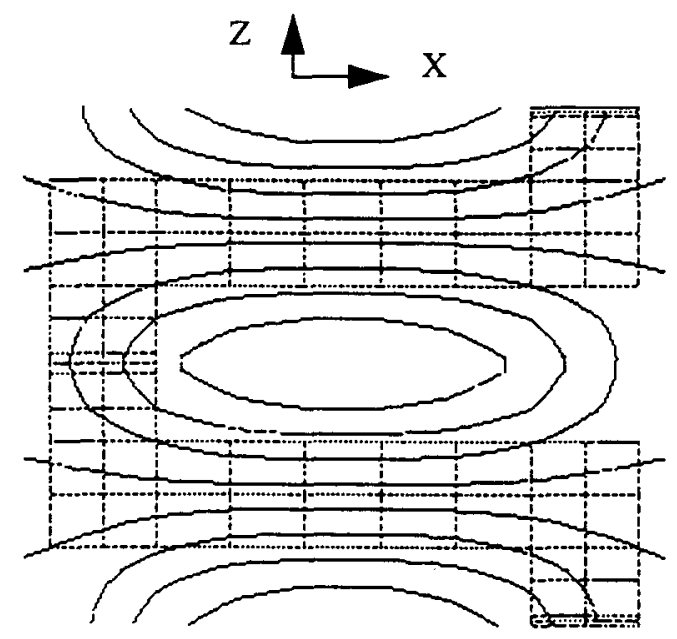

Figure 2: Contour plot of the flux density over one period. Lines show contours of equal $\mathrm{B}_{\mathrm{y}}$ in the $x-z$ plane. 


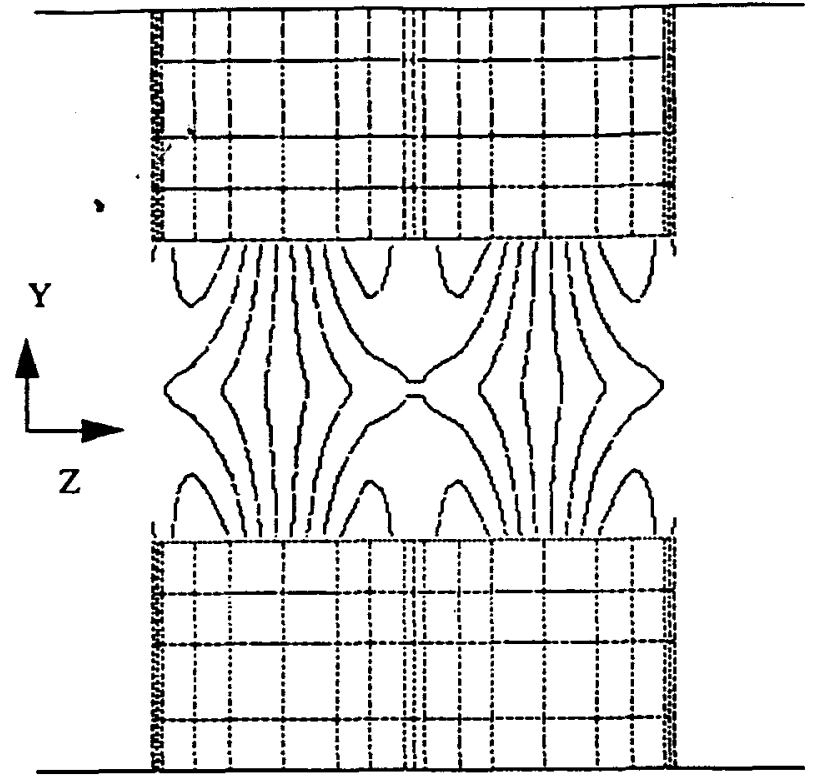

Figure 3: Contour plot of the flux density over one period. Lines show contours of equal $B_{y}$ in the $y-z$ plane.

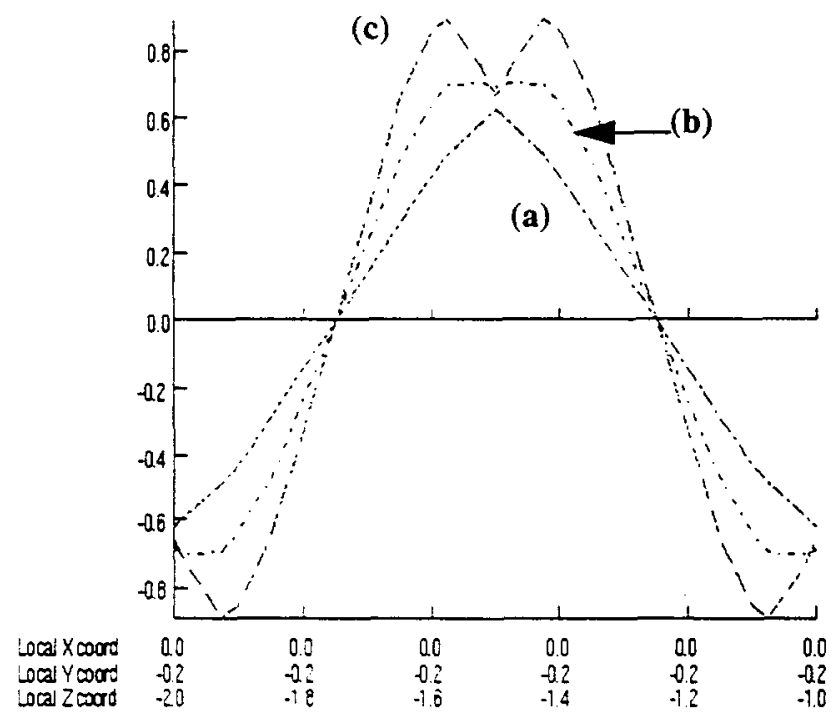

Figure 4: Field variation in the beam direction over one undulator period. Curve (a) is the field variation in the mid-plane. Curve (b) shows field variation 0.1 $\mathrm{mm}$ above or below the mid-plane. Curve (c) shows field variation $0.2 \mathrm{~mm}$ above or below the midplane. The field is weaker in the mid-plane since the gap between the poles $(0.6 \mathrm{~mm})$ is not small relative to the period of the undulator $(1 \mathrm{~mm})$ or the width of the poles $(0.7 \mathrm{~mm})$. The dip in the curve is due to a slot in the pole.

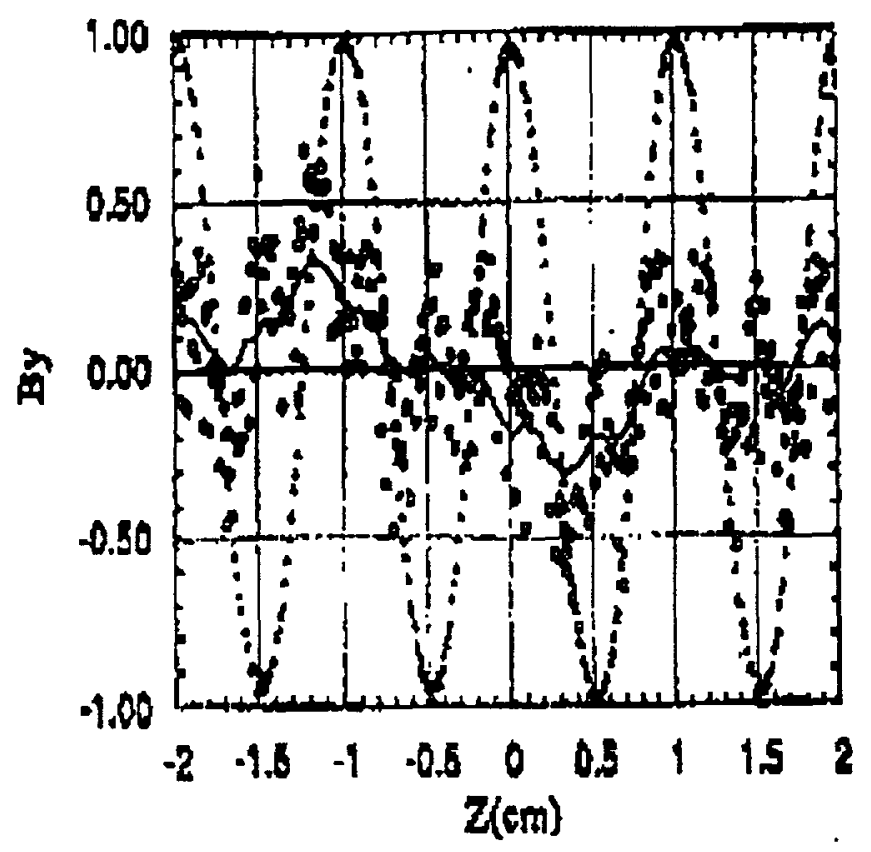

Figure 5: Measured field over the central region of the undulator. Circles show the measured field with a field of cosine variation subtracted, multiplied by a factor of ten. The solid line shows a smoothed fit to the circles.

\section{ACKNOWLEDGMENTS}

This work was supported by the U. S. Department of Energy, Office of Basic Science, under Contract No. W-31109-ENG-38. The first author would like to thank R. Kustom and J. Galayda for their support and encouragement. We also greatly benefited from various discussions with $F$. E. Mills of the Advanced Photon Source.

\section{REFERENCES}

[1] A. Nassiri, et. al., "A $50 \mathrm{MeV}$ mm-Wave Electron Linear Accelerator System for Production of Tunable Short Wavelength Synchrotron Radiation," Proc. of the IEEE International Electron Devices Meeting, Washington DC. pp. 116-120, December, 1993

[2] W. Ehrfeld, F. Gotze. D. Munchmerer, W. Schelb, and D. Schmidt. "LIGA Process: Sensor Construction Techniques via X-Ray Lithography," Technical Digest, IEEE Solid-State Sensor and Actuator Workshop. pp. 1-4. 1988

[3] H. Guckel, T.R. Christenson. K.J. Skrobis, D.D. Denton. B. Choi, E. G. Lovell, J. W. Lee. S. S. Bajikar, and T. W. Chapman,"Deep $X$-Ray and UV Lithographies for Micromechanics." Proc. of the IEEE Solid State Sensor and Actuator Workshop. pp. 118-122, 1990.

[4] L. R. Turner, A. Nassiri. F. E. Mills, S. Kim, and A. D. Feinerman."A Micro-undulator Fabricated by LIGA Process." IEEE Transactions on Magnetics. Vol. 32. No. 4. pp. 2602-2605. July 1996. 